\title{
STRUKTURAL ANALISIS MODEL PROSES PEMBELAJARAN DENGAN PENDEKATAN KEPUASAN LULUSAN: STUDI KASUS PADA TRACER STUDY PROGRAM STUDI ADMINISTRASI BISNIS
}

\author{
Andi Setiawan ${ }^{1}$, Suwardi, Khairul Saleh, Suharmanto \\ Jurusan Administrasi Bisnis, Politeknik Negeri Semarang, Semarang, Indonesia \\ email: ${ }^{1}$ andi_setiawan@polines.ac.id
}

\begin{abstract}
The current study was conducted to increase of our understanding of factors that influence distinctiveness of the curriculum as efforts to maintain and improve the quality of education in study program graduate of Business Administration. An extensive review of the existing literature was used to identify 32 factors that Affect quality of education and Alumni satisfaction. Data or a questionnaire distributed to 133 graduates study program graduate of Business Administration Department of Business Administration Polytechnic State Semarang. Of the 133 questionnaires distributed were returned as many as 124, and 9 questionnaires are not returned by the target date. The analysis of 124 questionnaires there are 13 questionnaires that occurred outlier. So the data or questionnaires that can be used for the study were as many as 111 questionnaires. Results from both the qualitative and quantitative phases of the current study demonstrated that 32 factors that Affect quality of education and Alumni satisfaction can be clustered into three basic process. First, based on the results of data analysis showed that the acquisition of specialized expertise is the key or most dominant variable, Second, results demonstrate mastery of tools and technology are the two variables that affect the realization of graduate satisfaction. Third, the results of data analysis showed that the formation of character and behavior of the third element in increasing the satisfaction of graduates through the value of the learning process The sectors in which the alumni study program graduate of Business Administration were not completely representative of reviews their year of graduation and geographical region. The findings suggest that, in order to increase of satisfaction study program graduate of Business Administration, Then focus on mastery of special skills is the most dominant variable that can affect the value of the learning process, This is a strength study program graduate of Business Administration, then the advice and recommendation is to maintain and emphasize the element of learning output is -unsur formed on the entire course, which relate directly and indirectly to the mastery of special skills in administration. This study contributes to the body of knowledge on the value of the learning process.
\end{abstract}

Keywords: Character and Behavior, Special Skills, Mastery Tools and Technology, Process Value education, graduate satisfaction

\section{STRUKTURAL ANALISIS MODEL PROSES PEMBELAJARAN DENGAN PENDEKATAN KEPUASAN LULUSAN: STUDI KASUS PADA TRACER STUDY PROGRAM STUDI ADMINISTRASI BISNIS}

\begin{abstract}
The current study was conducted to increase of our understanding of factors that influence distinctiveness of the curriculum as efforts to maintain and improve the quality of education in
\end{abstract}


study program graduate of Business Administration. An extensive review of the existing literature was used to identify 32 factors that Affect quality of education and Alumni satisfaction. Data or a questionnaire distributed to 133 graduates study program graduate of Business Administration Department of Business Administration Polytechnic State Semarang. Of the 133 questionnaires distributed were returned as many as 124, and 9 questionnaires are not returned by the target date. The analysis of 124 questionnaires there are 13 questionnaires that occurred outlier. So the data or questionnaires that can be used for the study were as many as 111 questionnaires. Results from both the qualitative and quantitative phases of the current study demonstrated that 32 factors that Affect quality of education and Alumni satisfaction can be clustered into three basic process. First, based on the results of data analysis showed that the acquisition of specialized expertise is the key or most dominant variable, Second, results demonstrate mastery of tools and technology are the two variables that affect the realization of graduate satisfaction. Third, the results of data analysis showed that the formation of character and behavior of the third element in increasing the satisfaction of graduates through the value of the learning process The sectors in which the alumni study program graduate of Business Administration were not completely representative of reviews their year of graduation and geographical region. The findings suggest that, in order to increase of satisfaction study program graduate of Business Administration, Then focus on mastery of special skills is the most dominant variable that can affect the value of the learning process, This is a strength study program graduate of Business Administration, then the advice and recommendation is to maintain and emphasize the element of learning output is -unsur formed on the entire course, which relate directly and indirectly to the mastery of special skills in administration. This study contributes to the body of knowledge on the value of the learning process.

Keywords: Character and Behavior, Special Skills, Mastery Tools and Technology, Process Value education, graduate satisfaction

\section{PENDAHULUAN}

Salah satu cara memastikan lulusan perguruan tinggi memiliki daya terima pasar tenaga kerja yang tinggi, adalah memastikan lulusan mereka memiliki ketrampilan kerja yang sesuai kebutuhan pasar. Karena bagi perusahaan tenaga kerja terdidik, akan menjamin perusahaan untuk terus dapat mempertahankan nilai keunggulan dan daya saing mereka. Namun jika hal ini tidak diperhatikan bukan tidak mungkin lulusan perguruan tinggi tidak akan direkrut oleh pasar, maka jika itu yang terjadi menandakan ada peluang bertambahnya jumlah pengangguran terdidik (Finch, Hamilton, Baldwin, \& Zehner, 2013). Studi Finch et al (2013) menunjukkan bahwa $40 \%$ pengusaha menyampaikan adanya gaps yang cukup beda antara kompetensi yang diinginkan pengusaha dengan kompetensi yang diajarkan di perguruan tinggi. Studi Wilkerson (2012) 2 mengarisbawahi bahwa terjadi gap yang sangat lebar antara keahlian yang dibutuhkan dalam melakukan pekerjaan dengan keahlian yang dimiliki oleh para alumni. Kondisi ini disebabkan kurikulum berjalan tidak selaras dengan perubahan kebutuhan pada pasar tenaga kerja. Survey kepada alumni menjadi hal yang penting bagi perguruan tinggi. Untuk itu rumusan kepuasan lulusan perlu mendapatkan masukan atau evaluasi dari para stakeholders (Soto dan Monticelli, 2107).

Permasalahan Kurikulum Prodi Administrasi Bisnis yang harus diteliti adalah rumusan dan penerapan kurikulum harus berdasarkan soft skill dan hard skill serta interpersonal. Model kepuasan lulusan merupakan salah satu desain model yang menawarkan pemecahan permasalahan Kurikulum Prodi Administrasi Bisnis. Berdasarkan temuan lapangan akan pelaksanaan Kurikulum Prodi Administrasi Bisnis oleh tim penelitian menunjukkan 
bahwa: 1). Belum pernah dilakukan tracer study atas Kurikulum Prodi Administrasi Bisnis secara lebih komperhensif; 2). Permasalahan banyaknya rumusan jumlah mata kuliah, banyaknya muatan materi teori dan praktek, jam pertemuan dll, sampai saat ini belum pernah divalidasi oleh alumni; dan 3). Ketersediaan informasi yang terbatas akan keberhasilan para alumni dan evaluasi akan kinerja mereka berdasarkan keahlian yang didapat dari prodi semasa kuliah dulu.

Kondisi ini sangat mengkhawatirkan semua pihak, jika Kurikulum Prodi Administrasi Bisnis tidak lagi menjadi input, proses dan output yang dapat diharapkan dan dihandalkan. Maka dapat dibayangkan tumpukan permasalahan yang saat ini dihadapi Manajemen Prodi Administrasi Bisnis dalam upaya meraih mutu Akreditasi A. Berdasarkan alasan tersebut, penelitian ini mengusul permasalahan penelitian yaitu Bagaimana sebuah permodelan structural menjelaskan kepuasan lulusan dalam upaya meningkatkan mutu pendidikan secara berkelanjutan.

\section{Tinjauan Pustaka}

\section{Nilai Proses Pembelajaran}

Proses pembelajaran dikatakan bernilai karena mereka memiliki kompetensi yang sesuai dengan keinginan atau bahkan melebih harapan para pengguna (User). Chen et al (2010) Perusahaan saat ini keberatan untuk membimbing karyawan untuk menjadi unggul. Karena efefiensi dan efektiftas mereka untuk mencapai tujuan membuat mereka menjadi selektif dalam memilik calon karyawannya. Hal tersebut berarti bahwa seorang karyawan dikatakan dikatakan professional dikarenakan telah memenuhi kualifikasi kompentensi yang dibutuhkan. Dan kesemua itu dihasilkan oleh perguruan tinggi (Beisenbekova dan Kazangapova, 2015; Naveed, 2014). Menurut Fahrutdinova et al (2016) adalah lulusan harus menunjukkan sejumlah kompetensi, beberapa diantaranya berkaitan dengan pengoperasian pemikiran budaya, kemampuan menganalisa
Informasi dan kesiapan untuk mengadopsi solusi organisasi dan manajerial dalam menghadapi situasi yang tidak biasa.

\section{Karakter dan Perilaku}

Pembentukan watak dan sikap adalah sebuah proses panjang, dan proses ini tidak bisa ditranformasikan lewat memberian pengetahuan. Interpersonal hanya dapat dibentuk dari sebuah proses perilaku yang ditanamkan dan dipraktekan secara terus menerus (Eby et al 2013). Ketidakmampuan lulusan dalam bekerja, dari banyak penelitian sebelumnya ditentukan bukan oleh hard skill atau soft skill mereka, tetapi dari watak dan sikap mereka saat bekerja. Çelen et al (2014) menegaskan bahwa kehadiran konflik pada organisasi dan anggotanya tidak mungkin dihindari atau bahkan dihilangkan. Pembentukan watak dan sikap dari lulusan (alumni) sesuai harapan stakeholders, khususnya industri adalah elemen dasar (Virga et al 2014).

\section{Keahlian Khusus}

Proses perubahan seorang siswa diawali dari transfer sederhana pengetahuan, keterampilan dan kemampuan dalam proses pembelajaran ke pembentukan dan pengembangan kompetensi profesional siswa. Peningkatan sistem pendidikan tinggi didefinisikan sebagai tingkat tertentu kemampuan bahasa, ucapan dan pengetahuan, keterampilan dan kemampuan sosial budaya itu. Penguasaan kompetensi generic seperti komunikasi (bahasa), kearsipan, perkantoran dan lain sebagainya, ini akan memungkinkan untuk bervariasi diterima dan tepat perilaku yang bernilai mereka dalam melaksanakan pekerjaan secara professional (Fahrutdinova et al 2016; Otok dan Foldspang, 2016).

\section{Penguasaan Alat dan Teknologi}

Tuntutan modernisasi lingkungan pendidikan salah satu tujuan utamanya adalah meningkatkan kualitas pendidikan tinggi. Inti perubahan itu sendiri adalah bergerak menyesuaikan kebutuhan dan harapan. 
Dewasa ini kehadiran teknologi secara umum, khususnya teknologi informasi. Keberadaan teknologi komunikasi mengambil bagian dalam setiap bidang kehidupan, adalah teknologi yang memungkinkan mengirimkan informasi tanpa waktu, tempat, dan jarak. Pada sector usaha kehadiran teknologi komunikasi adalah mutlak. Oleh sebab itu, pada satu sisi perguruan tinggi dituntut menguasai teknologi informasi. Pada saat bersamaan penggunaan teknologi di bidang pendidikan telah mempengaruhi struktur sistem pendidikan (Eskicumali et al 2015).

\section{Hipotesis Penelitian}

Rumusan hipotesis penelitian ini adalah sebagai berikut;

Hipotesis $1_{1}$ : "Pembentukan karakter dan perilaku pada Prodi Administrasi Bisnis berpengaruh positip terhadap nilai proses pembelajaran Prodi Administrasi Bisnis".

Hipotesis 2 : "Penguasaan keahlian khusus pada Prodi Administrasi Bisnis berpengaruh positip terhadap nilai proses pembelajaran Prodi Administrasi Bisnis “.

Hipotesis $_{3}$ : "Penguasaan alat dan teknologi pada Prodi Administrasi Bisnis berpengaruh positip terhadap nilai proses pembelajaran Prodi Administrasi Bisnis".

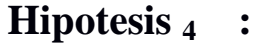

$\begin{array}{lr}\text { "Nilai } & \text { proses } \\ \text { pembelajaran } & \text { pada Prodi } \\ \text { Administrasi } & \text { Bisnis } \\ \text { berpengaruh } & \text { positip } \\ \text { terhadap } & \text { Kepuasan } \\ \text { lulusan". } & \end{array}$

\section{METODE PENELITIAN}

Sebuah tinjauan ekstensif dari literatur yang ada dan desain analisis kausalitas yang digunakan untuk mengidentifikasi 32 faktor yang Mempengaruhi kualitas pendidikan dan Alumni kepuasan. Data atau kuesioner yang dibagikan kepada program studi 133 lulusan Administrasi Bisnis Jurusan Administrasi Bisnis Politeknik Negeri Semarang. 133 kuesioner yang disebarkan dikembalikan sebanyak 124, dan 9 kuesioner tidak dikembalikan oleh target. Dari 124 kuesioner ada 13 kuesioner yang terjadi outlier. Jadi data atau kuesioner yang dapat digunakan untuk penelitian ini adalah sebanyak 111 kuesioner. Penelitian ini menggunakan metode survei dengan mempergunakan kuesioner sebagai media bantu baik metode tertutup maupun terbuka. Pernyataanpernyataan dalam kuesioner ini dibuat dengan menggunakan skala 1-10 (Sangat tidak setuju, Tidak setuju, Kecenderungan setuju lebih kecil, Kecenderungan setuju kecil, Kecenderungan setuju, Keyakinan setuju, Kecenderungan setuju besar, Kecenderungan setuju sangat besar, Setuju dan Sangat setuju) untuk mendapatkan data yang bersifat interval dan diberi skor atau nilai.

Dimensi pengukuran konstruk karakter dan perilaku diindikasikan dari 10 (sepuluh) indikator yaitu: displin $\left(\mathrm{X}_{1}\right)$, semangat berprestasi $\left(\mathrm{X}_{2}\right)$, sopan santun $\left(\mathrm{X}_{3}\right)$, kreativitas $\left(\mathrm{X}_{4}\right)$, bertanggungjawab $\left(\mathrm{X}_{5}\right)$, mendukung $\left(\mathrm{X}_{6}\right)$, menghargai $\left(\mathrm{X}_{7}\right)$, adaptabilitas $\left(\mathrm{X}_{8}\right)$, kemandirian $\left(\mathrm{X}_{9}\right)$ dan bekerjasama $\left(\mathrm{X}_{10}\right)$; Dimensi pengukuran konstruk Keahlian khusus adalah: Perkantoran $\left(\mathrm{X}_{11}\right)$, Kesekretariatan $\left(\mathrm{X}_{12}\right)$, Publik Relation $\left(\mathrm{X}_{13}\right)$, Pengarsipan $\left(\mathrm{X}_{14}\right)$, Komunikasi Bisnis $\left(\mathrm{X}_{15}\right)$, Bahasa asing $\left(\mathrm{X}_{16}\right)$, Administasi $\left(\mathrm{X}_{17}\right)$, Pengolahan Data Bisnis $\left(\mathrm{X}_{18}\right)$ dan Wirausaha $\left(\mathrm{X}_{19}\right)$. Dimensi pengukuran konstruk Penguasaan alat dan teknologi adalah Untuk pengetikan dokumen $\left(\mathrm{X}_{20}\right)$, Untuk Penawaran Bisnis $\left(\mathrm{X}_{21}\right)$, Untuk pengelolaan arsip $\left(\mathrm{X}_{22}\right)$, Untuk administrasi $\left(\mathrm{X}_{23}\right)$ dan Untuk surat menyurat $\left(\mathrm{X}_{24}\right)$. Dan Dimensi pengukuran konstruk Nilai proses pembelajaran adalah sebagai berikut: Nilai ekonomi $\left(\mathrm{X}_{25}\right)$, Nilai kapabilitas $\left(\mathrm{X}_{26}\right)$, Nilai profesionalitas $\left(\mathrm{X}_{27}\right)$ dan Nilai pengembangan 
$\left(\mathrm{X}_{28}\right)$. Serta Dimensi pengukuran konstruk Kepuasan lulusan yaitu Senang $\left(X_{29}\right)$, Referensi $\left(X_{30}\right)$, Sikap membela $\left(X_{31}\right)$ dan Partisipasi aktif $\left(\mathrm{X}_{32}\right)$. Tehnik analisis data pada penelitian ini akan mengunakan dua pendekatan: 1). Confirmatory factor analysis, pada Structural Equation Modeling (SEM) yang mengunakan paket komputerisasi AMOS 22.0 dalam hal ini untuk mengkonfirmasi faktor-faktor yang paling dominan dalam satu kelompok variabel. 2). Regression Weight pada Structural Equation Modeling (SEM) yang digunakan untuk meneliti seberapa besar hubungan antar variabel. Selain dua pendekatan di atas, penelitian ini juga melakukan uji reliabilitas, uji validitas, uji analisis dekripsi indek, dan lain-lain.

\section{HASIL YANG DICAPAI}

Analisis Structural Equation Model (SEM) secara Full Model yang dimaksudkan untuk menguji model dan hipotesis yang dikembangkan dalam penelitian ini. Pengujian model dalam Structural Equation Model dilakukan dengan dua pengujian, yaitu uji kesesuaian model dan uji signifikansi kausalitas melalui uji koefisien regresi. Setelah melalui tahapan analisis konfirmatori konstruk eksogen dan endogen yang loudingnya di atas 0,5 memenuhi kriteria normal dan memenuhi goodness of fit. Full model masih memenuhi criteria fit, seperti disajikan pada Gambar 1.

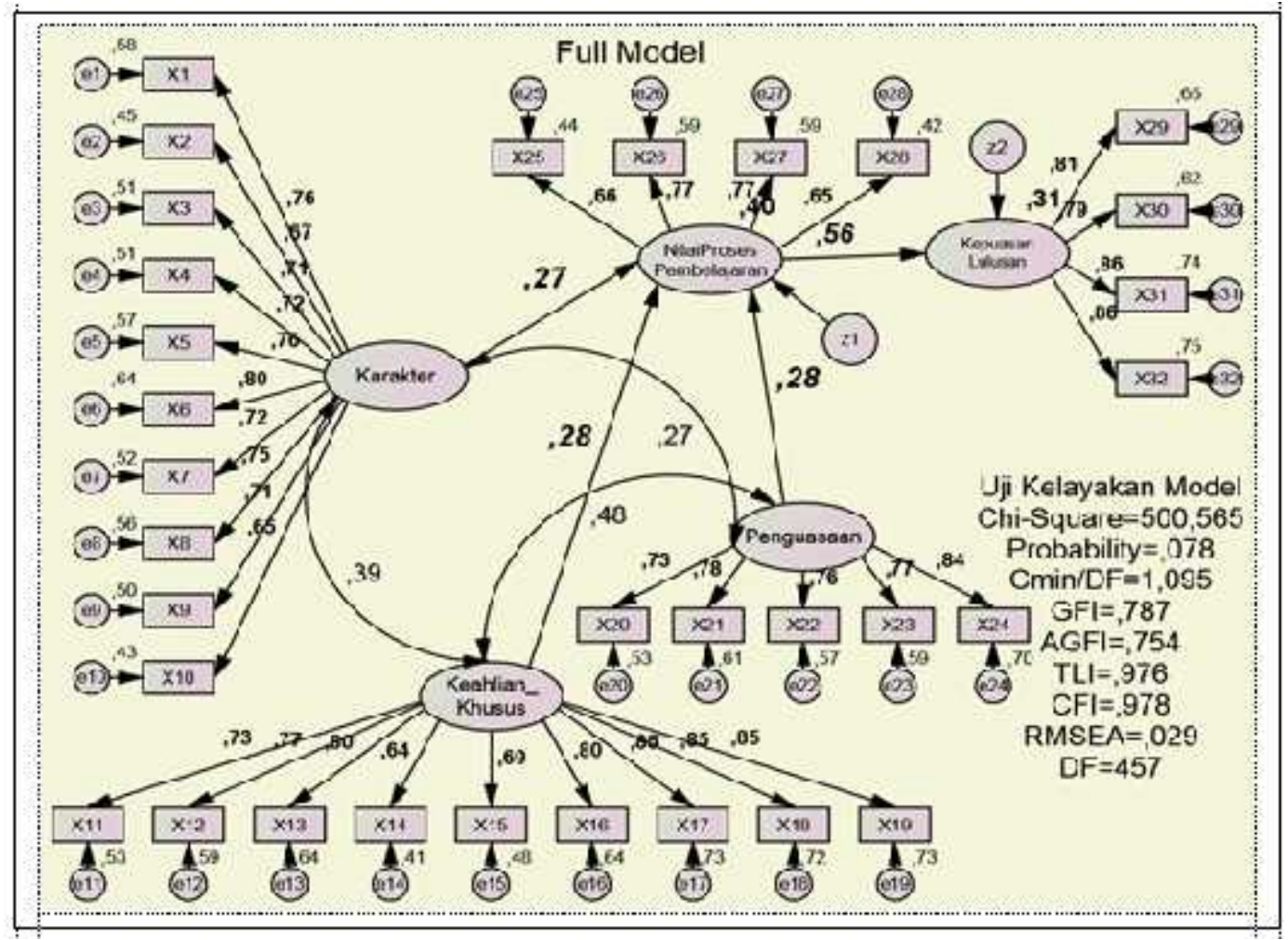

Sumber: data primer yang diolah, 2018

Gambar 1 Hasil Uji Structural Equation Modelling

Berdasarkan Gambar 1 berupa analisis full model, dapat dilihat bahwa tingkat signifikansi sebesar 0,078 menunjukkan bahwa hipotesis nol $\left(\mathrm{H}_{0}\right)$ yang menyatakan bahwa tidak ada perbedaan antara matriks kovarians sampel dengan matriks kovarians 
populasi yang diestimasi tidak dapat ditolak. Hasil tersebut menunjukkan diterimanya hipotesis nol $\left(\mathrm{H}_{0}\right)$ atau model ini dapat diterima, yaitu terdapat enam konstruk yang berbeda dengan indikator-indikatornya. Selain pengujian berdasarkan nilai probability perlu juga diperkuat dengan nilai - nilai yang lain, seperti pada Tabel 1.

Tabel 1 Hasil Uji Full Model

\begin{tabular}{|c|c|c|c|}
\hline Kriteria & Cut of Value & Hasil & Evaluasi \\
\hline Chi-Square & $\chi^{2}$ dengan df : $457 ; p: 5 \%=507,839$ & 500,565 & Baik \\
\hline Probability & $\geq 0,05$ & 0,078 & Baik \\
\hline GFI & $\geq 0,90$ & 0,787 & Marginal \\
\hline AGFI & $\geq 0,90$ & 0,754 & Marginal \\
\hline TLI & $\geq 0,95$ & 0,976 & Baik \\
\hline CFI & $\geq 0,95$ & 0,978 & Baik \\
\hline CMIN/DF & $\leq 2,00$ & 1,095 & Baik \\
\hline RMSEA & $\leq 0,08$ & 0,029 & Baik \\
\hline
\end{tabular}

Sumber: data primer yang diolah, 2018

Berdasarkan hasil pengamatan pada gambar pada grafik analisis full model dapat ditunjukkan bahwa model memenuhi kriteria fit, hal ini ditandai dengan nilai dari hasil perhitungan sebagian besar memenuhi kriteria (baik) atau layak full model. Hasil tersebut menunjukkan bahwa model keseluruhan memenuhi kriteria model fit.

Tabel 2 Hasil Regression Weights Analisis Struktural Equation Modeling

\begin{tabular}{|c|c|c|c|c|c|c|c|}
\hline & & & Estimate & S.E. & C.R. & $\mathrm{P}$ & Label \\
\hline NilaiProses_Pembelajaran & $<---$ & Karakter & ,233 & ,094 & 2,486 & ,013 & par_28 \\
\hline NilaiProses_Pembelajaran & $<--$ & Keahlian_Khusus & ,280 &, 118 & 2,382 & 017 & par_29 \\
\hline NilaiProses_Pembelajaran & $<--$ & Penguasaan &, 251 &, 105 & 2,394 & 017 & par_30 \\
\hline Kepuasan_Lulusan & $<---$ & NilaiProses_Pembelajaran & ,812 &, 182 & 4,458 & $* * *$ & par_31 \\
\hline
\end{tabular}

Sumber : data primer yang diolah, 2018

Berdasarkan Gambar 1 dan Tabel 2 bahwa setiap indikator pembentuk variabel laten menunjukkan hasil yang memenuhi kriteria yaitu nilai $\mathrm{CR}$ di atas 1,96 dengan $\mathrm{P}$ lebih kecil dari pada 0,05 dan nilai lambda atau factor loading yang lebih besar dari 0,5 . Hasil tersebut dapat dikatakan bahwa indikatorindikator pembentuk variabel laten tersebut secara signifikan merupakan indikator dari faktor-faktor laten yang dibentuk. Sehingga dapat disimpulkan bahwa model yang dipakai dalam penelitian ini dapat diterima. Setelah tahap - tahap pengujian dilakukan, langkah selanjutnya adalah pengujian hipotesis penelitian yang diajukan pada bab sebelumnya. Selanjutnya hasil uji dari tiaptiap hipotesis di atas akan disajikan secara ringkas pada Tabel 3 tentang kesimpulan hipotesis. 
Tabel 3 Ringkasan Hasil Pengujian Hipotesis

\begin{tabular}{llll}
\hline & \multicolumn{1}{c}{ HIPOTESIS } & \multicolumn{1}{c}{ Nilai CR dan } & \multicolumn{1}{c}{ HASIL } \\
& & \multicolumn{1}{c}{ P } & \multicolumn{1}{c}{ UJI } \\
\hline Hipotesis & Karakter berpengaruh positif terhadap Nilai & $\mathrm{CR}=2,486$ & Diterima \\
& Proses Pembelajaran & $\mathrm{P}=0,013$ & \\
Hipotesis $_{2}$ & Keahlian khusus berpengaruh positif & $\mathrm{CR}=2,382$ & Diterima \\
& terhadap Nilai Proses Pembelajaran & $\mathrm{P}=0,017$ & \\
Hipotesis & Penguasaan berpengaruh positif terhadap & $\mathrm{CR}=2,394$ & Diterima \\
& Nilai Proses Pembelajaran & $\mathrm{P}=0.017$ & \\
Hipotesis & Nilai Proses Pembelajaran berpengaruh & $\mathrm{CR}=4,458$ & Diterima \\
& positif terhadap Kepuasan lulusan & $\mathrm{P}=0,000$ & \\
\hline
\end{tabular}

Sumber: data primer yang diolah, 2018

\section{KESIMPULAN DAN SARAN Kesimpulan}

Hasil pengujian hipotesis menunjukkan bahwa semua hipotesis diterima. Kesimpulan atas masalah penelitian didasarkan atas temuan permasalahan penelitian yang teridentifikasi dan tersusun pada sebelumnya. Hasil dari temuan penelitian ini berdasarkan hasil analisis data yang tergambar pada grafik analisis full model (Gambar 1) membuktikan dan memberi kesimpulan yaitu melalui 3 (tiga) proses dasar kepuasan lulusan akan dapat meningkat sesuai dengan harapan antara lain, yaitu: Pertama, berdasarkan hasil analisis data menunjukkan bahwa akuisisi keahlian khusus adalah kunci atau paling dominan variabel. Kedua, Hasil menunjukkan penguasaan alat dan teknologi adalah dua variabel yang mempengaruhi realisasi kepuasan lulusan. Ketiga, hasil analisis data menunjukkan bahwa pembentukan karakter dan perilaku elemen ketiga dalam meningkatkan kepuasan lulusan melalui nilai dari proses belajar.

\section{Saran}

Berikut ini diuraikan beberapa saran alternatif yang bersifat strategis:

a. Pada mata kuliah praktik seperti pengetikan, administrasi perkantoran, simulasi bisnis dll, selain pengetahuan dan ketrampilan, maka "Kerapian, Ketelitian dan Kecepatan" menjadi indikator lain yang menjadi tolok ukur nilai keunggulan lulusan Prodi Administrasi Bisnis.

b. Prodi ini seharusnya menekankan pada cara pandang yang keluar dari zona aman (out of the box), di mana "budaya mencari kerja harus dirubah dengan budaya menciptakan pekerjaan" setidaktidaknya untuk dirinya sendiri. Keberminatan lulusan akan praktik wirausaha, harus didukung dengan muatan profil wirausaha pada proses pembelajaran akan mental, pengetahuan dan keahlian dibidang ilmu selain kewirausahaan seperti, keuangan, pemasaran, penjualan dll.

c. Khususnya keberanian lulusan untuk berbicara bahasa asing. Maka saran dan rekomendasi adalah (1). Menciptakan program sehari berbahasa asing pada prodi ini; (2). Praktik pada mata kuliah selain bahasa asing (Inggris, mandarin dan jepang) diupayakan lebih mengedepankan pada muatan materi dan sumber referensi yang mempergunakan bahasa asing misalnya buku-buku, jurnal dan sumber pustaka lainnya; dan (3). Tetap mempertahankan Score TOEFL tertentu menjadi syarat wajib lulusan prodi ini, misalnya Score TOEFL 450.

d. Kemampuan penguasaan alat dan teknologi untuk surat menyurat bisnis menjadi, maka saran dan rekomendasi adalah (1). Menanamkan dasar-dasar korespondensi dengan baik; (2). Mata kuliah terkait korespondensi lebih banyak 
praktik dalam surat-menyurat dengan berbagai bantuan teknologi modern; dan (3). Pengelolaan membangun sistem komunikasi berbasis korespondensi eletronik dan email mengabdosi seperti yang dilakukan oleh PT Freeport Indonesia.

e. Berhubungan dengan indikator Kemandirian maka saran dan rekomendasi adalah (1). Penekanan pada setiap karakter dan perilaku kemandirian sebagai output sikap dalam setiap kurikulum pada prodi selanjutnya menjadi salah satu komponen evaluasi penilaian mahasiswa; (2). Menyusun jobsheet pada seluruh mata kuliah, khususnya berbasis teori lebih banyak dibandingkan muatan praktiknya; dan (3). Mempertahankan kerjasama dengan industri, sebagai pembimbing magang dalam mengukur tingkat insiatif mahasiswa ketika praktik kerja lapangan.

\section{Agenda Penelitian Mendatang}

Beberapa agenda penelitian mendatang yang dapat diberikan dari penelitian ini antara lain, adalah : 1). Penelitian ke depan dapat diperluas uji kepuasan pengguna (end user/perusahaan) prodi Administrasi Bisnis, sehingga hasilnya dapat lebih memperkaya, memperkuat terori dan riset terdahulu; 2). Untuk memperbaiki koefisiensi persepsi karakter dan perilaku, keahlian khusus dan penguasaan alat dan teknologi yang sesuai loading factor yang ideal yaitu $\geq 0.50$, misalnya ke depan perlu memperluas dan menambah variabel seperti sarana dan prasarana pendidikan dalam penelitian yang akan datang. Dan 3). Penelitian ke depan perlu mengupayakan agar instrumen pengujian kesesuaian model penelitian dapat memenuhi setidak-tidaknya kriteria nilai $\mathrm{R}$ Square $\left(\mathrm{R}^{2}\right)$ yang lebih tinggi atau dengan menemukan variabel intervening lain untuk menjadi baik, melakukan penambahan dan pengurangan baik variabel dan indikator dalam penelitian ini. Sehingga hasil penelitian yang akan datang diharapkan menjadi lebih baik dan mampu penyempurnakan kekurangan atau keterbatasan dalam penelitian ini

\section{DAFTAR PUSTAKA}

Beisenbekova, Gulmira B., and Syrgaly O. Kazangapova (2015)," The Main Peculiarities Of Concepts "Qualification", "Competence", "Professional Competence", EDUCATION and SCIENCE without borders, pp. 1-3

Çelen, Özay \& Abdulkadir Teke \& Necmettin Cihangiroglu (2014) The Effect of Socio Cultural Characteristics on the Effectiveness of Teamwork: A Study in the Gülhane Military Medical Faculty Training Hospital", J Med Syst, pp. $38: 126$

Chen, Hai Ming., And Wen Yen Chang, (2010)," The essence of the competence concept: Adopting an organization's sustained competitive advantage viewpoint", Journal of Management \& Organization, Vol. 16: 677-699.

Eby, Ruth A., Patricia Lynn Hartley., Patricia Jeanne Hodges., Rebecca Hoffpauir., Shirlene Newbanks., and Jane H. Kelley (2013), "Moral Integrity and Moral Courage: Can You Teach It? ", Journal of Nursing Education, Vol. 52, No. 4, pp. 229-233

Eskicumali, Ahmet., Serhat Arslan., Zeynep Demirtas (2015)," Utilization of Information and Communication Technologies as a Predictor of Educational Stress on Secondary School Students", TOJET: The Turkish Online Journal of Educational Technology April, volume 14 issue 2, pp. 241-246

Fahrutdinova, Rezida Ahatovna. , and Irina Dmitrievna Vasileva (2016)," The Foemation Of Foreing Communicative Competence As The Basis Of Professional Competence Of Future Teacher Of Forieng Language," Journal of Organizational Culture, 
Communications and Conflict, Volume 20, pp. 209-214

Finch, D. J., Hamilton, L. K., Baldwin, R., \& Zehner, M. (2013). An exploratory study of factors affecting undergraduate employability. Education \& Training, 55(7), 681-704.

Naveed, T. A., Jabeen, T., \& Ullah, S. (2014). An appraisal of mismatch between employers' expectations and graduating students' perception about employability skills; A case study of gujrat (pakistan). The Pakistan Journal of Social Issues, 5, 90-109.

Otok, Robert ., and Anders Foldspang (2016)," Main competences and skills to perform Essential Public Health Operations, offered by Schools of Public Health in four European countries: a short pilot report", Int $J$ Public Health, Vol. 61, pp. 633-639

Soto, Fábio Dal., And Jefferson Marlon Monticelli (2017)," Coopetition Strategies In The Brazilian Higher Education', RAE-Revista de Administração de Empresas | FGV EAESP, pp 65-78

Virga, Delia., Petru Lucian CurS., Laurent, iu Maricut., Florin A. Sava., Silvia Ma gurean., and Irina Macsinga (2014)," Personality, Relationship Conflict, and Teamwork Related Mental Models

Wilkerson, Jerod W. (2012)," An Alumni Assessment of MIS Related Job Skill Importance and Skill Gaps", Journal of Information Systems Education, Vol. $23(1$,

pp.85-97 
Setiawan, dkk/AdBis 20 (1): 1 - 10 